\title{
Daily energy intake seen in obese Kashmiri population and compare the same with Recommended dietary allowances as per ICMR guidelines
}

\author{
${ }^{1}$ Dr. Ibrar Bashir Sherazi, ${ }^{2}$ Dr. Mohd. Farooq Mir, ${ }^{3}$ Dr. Sajad Hamid, \\ ${ }^{4}$ Dr.M.Rafiq, ${ }^{5}$ Dr. Shahnawaz Hamid \\ ${ }^{I}$ Department of Community medicine, SKIMS Medical college,Bemina,Kashmir,India \\ ${ }^{2}$ Consultant Radiology, SKIMS Medical College, Bemina \\ ${ }^{3}$ Lecturer Anatomy, SKIMS Medical college, Bemina, Srinagar,India \\ ${ }^{4}$ Associate Professor, Community medicine, SKIMS Medical college \\ ${ }^{5}$ Post-graduate, SKIMS Soura.
}

\begin{abstract}
:
AIM: Daily energy intake seen in obese Kashmiris aged 18-45 years and compare the same for Recommended dietary allowances of Indians as per ICMR guidelines

Materials and Methods: Multistage and multiphasic sampling technique was utilized in this study based on WHO classification of obesity according to BMI of 18-45 years of age. Each household was visited and only the subjects having age of 18-45 years were included in this study and this comprised of 5107 subjects, then identified obese cases with the help of height and weight techniques. Only those people who had simple obesity were included in the study. All the obese respondents were asked to report all foods and beverages consumed over the previous 24 hour time period (midnight to midnight). For accuracy, respondents were first asked to recall all food items in an uninterrupted manner, and then specific probes for the types of foods, preparation ingredients, and the amount were verified for the food items mentioned.The portion sizes were converted into grams before the data entry, and the energy intake was compared with the recommended dietary allowances for Indians by Indian Council of Medical Research (ICMR), 2009. An unquantified food frequency questionnaire (FFQ) was developed to assess the usual dietary intake over a week period to minimize the effect of day-to-day variation in dietary intake. The data was collected and analyzed statistically.RESULTS: Among obese males, if life style is sedentary the requirement was $2320 \mathrm{kcal} /$ day \& deviation seen is $+207 \mathrm{kcal} /$ day. For moderate work ,requirement is $2730 \mathrm{kcal} /$ day \& deviation was $+243 \mathrm{kcal} /$ day \& for heavy work, requirement is $3490 \mathrm{kcal} /$ day and the deviation seen was $+282 \mathrm{kcal} / \mathrm{day}$.Among obese females, if life style is sedentary the requirement was $1900 \mathrm{kcal} /$ day \& deviation seen is $+337 \mathrm{kcal} /$ day. For moderate work , requirement is $2230 \mathrm{kcal} /$ day \& deviation was $+171 \mathrm{kcal} /$ day \& for heavy work, requirement is $2850 \mathrm{kcal} /$ day and the deviation seen was +249 kcal/day.CONCLUSION: As populations become more urban and incomes rise, diets high in sugar, fat and animal products replace more traditional diets that were high in complex carbohydrates and fibre. Unique traditional food habits are being replaced by westernized fast foods, soft drinks and increased meat consumption. Homogenizations and westernization of the global diet has increased the energy density.
\end{abstract}

Key words: obesity, calorie, dietary intake, recommended dietary allowances,

\section{Introduction}

Obesity is one of the oldest documented metabolic disturbances in the medical history. Historical evidence for obesity is found in Egyptian mummies in Greek sculpture. This abnormality has persisted throughout the centuries, which have been characterized by markedly different environmental stresses and dietary habits ${ }^{1}$

Obesity is a nutritional disorder that spans all ages and ethnicities and affects both sexes. World health organization (WHO) in 2000 called an international consultation on obesity to review epidemiological data worldwide, which concluded that obesity is a rapidly growing epidemic and at the same time acknowledged its status as disease. ${ }^{2}$

Due to obesity, many complications arises like Diabetes Mellitus type 2, Hypertension, Stroke, Hyperlipidaemia,Osteoarthritis, Coronary heart diseases, Cancer (Post menopausal breast carcinoma, endometrial, Ovarian, Gall-bladder and colon), Gall stones, sleep Apnea. ${ }^{3,4,5,6}$.

obesity can be divided into simple obesity, secondary obesity and drug-induced obesity.Simple Obesity- primary obesity, is due to excessive energy intake and too little consumption, also known as dietinduced obesity and has the largest proportion in all types of obesity(95\%). The simple obesity are generally caused by the heredity factor, the nutrition surplus and a lack of exercise, and characterized by the even 
distribution of the whole body fat. It is certain that any factor likely cause simple obesity as long as they can make energy intake more than energy consumption. These factors include eating too much, too little physical activity, psychosocial factors, genetic factors, and so on. Secondary obesity: is metabolic disorder Where in addition to obesity there are variety of clinical manifestations, such as Cushing's disease .Drug-induced obesity.For example, the use of adrenal cortex hormones drugs (such as prednisone, dexamethasone and hydrocortisone, etc.) to treat anaphylactic disease In general, when patients stop using these drugs, obesity will disappear by itself.

The prevalence of obesity is increasing throughout the world's population. But the distribution varies greatly between and within countries. In the US, over the past 30 years, the prevalence of obesity rose from about $12-20 \%$ of the population from 1978 to 1990 .

The UK has experienced an increase in the prevalence of obesity from $7 \%$ in 1980 to $16 \%$ in $1995^{7}$. In Asia, the prevalence of obesity has rapidly increased ${ }^{8,9}$. The obesity epidemic moves through a population in a reasonably consistent pattern over time and this is reflected in the different patterns in low- and high income countries. In low income countries, obesity is more common in people of higher socioeconomic status and in those living in urban communities. It is often first apparent among middle-aged women. In more affluent countries, it is associated with lower socioeconomic status, especially in women, and rural communities ${ }^{10,11}$. The sex differences are less marked in affluent countries and obesity is often common amongst adolescents and younger children. Women in all regions are generally more obese than men and the prevalence for those on low income is still increasing. The increasing westernization, urbanization and mechanization occurring in most countries around the world is associated with changes in the diet towards one of high fat, high energy-dense foods and a sedentary lifestyle ${ }^{7,12}$. This shift is also associated with the current rapid changes in childhood and adult obesity. Even in many low income countries, obesity is now rapidly increasing, and often coexists in the same population with chronic under nutrition ${ }^{12}$. Life expectancy has increased due to advancement in nutrition, hygiene and the control of infectious disease. Infectious diseases and nutrient deficiency diseases are, therefore, being replaced in developing countries by new threats to the health of populations like obesity, cardiovascular disease and diabetes ${ }^{7} \mathrm{~A}$ sharp decline in cost of vegetable oils and sugar means that they are now in direct competition with cereals as the cheapest food ingredients in the world ${ }^{13}$. This has caused a reduction in the proportion of the diet that is derived from grain and grain products ${ }^{12}$ and has greatly increased world average energy consumption, although this increase is not distributed evenly throughout the world's population ${ }^{13}$.

As populations become more urban and incomes rise, diets high in sugar, fat and animal products replace more traditional diets that were high in complex carbohydrates and fibre ${ }^{12,13}$. Ethnic cuisine and unique traditional food habits are being replaced by westernized fast foods, soft drinks and increased meat consumption. Homogenizations and westernization of the global diet has increased the energy density ${ }^{13}$ and this is particularly a problem for the poor in all countries who are at risk of both obesity and micronutrient deficiencies ${ }^{11}$. Health consequences of obesity is that the Mortality rates increase with BMI and they are greatly increased above a BMI of $30 \mathrm{~kg} / \mathrm{m}^{2}{ }^{14}$. The most potent predictor for the risk of diabetes, apart from age, is the BMI ${ }^{14}$. Now in many populations around the world, a substantial proportion of the teenagers with diabetes have the obesity-associated type 2 variety. Asian populations appear to develop diabetes at a lower BMI than other populations .

A high BMI is associated with higher blood pressure and risk of hypertension, higher total cholesterol, LDLcholesterol and triglyceride levels and lower HDLcholesterol levels. The overall risk of coronary heart disease and stroke, therefore, increases substantially with weight gain and obesity ${ }^{14}$. Gall bladder disease and the incidence of clinically symptomatic gallstones are positively related to BMI ${ }^{14}$.There is evidence to suggest that there is increased cancer risk as BMI increases, such as colorectal cancer in men, cancer of the endometrium and biliary passage in women, and breast cancer in post-menopausal women ${ }^{7,14}$. Obese people are also at increased risk of gout, sleep apnoea, obstetric and surgical complications ${ }^{14}$. The direct costs of obesity are predominantly from diabetes, cardiovascular disease and hypertension. Indirect costs, which are far greater than direct costs, include workdays lost, physician visits, disability pensions and premature mortality which all increases as BMI increases ${ }^{15}$. Intangible costs (impaired quality of life) have not been estimated, but given the social and psychological consequences of obesity, they are likely to be enormous.Potential aetiological factors in relation to obesity in populations The format for identifying potential nutritional causes of obesity at a population level is based on the Epidemiological Triad ${ }^{16}$ where the 'hosts' are the general population, the 'vectors' are the foods and nutrients and the 'environment' includes the physical, economic, policy and socio-cultural factors external to the individual.

There is evidence from the US that snacking prevalence (i.e. occasions of snacking) is increasing, the energy density of snack foods is increasing and the contribution to total energy is increasing ${ }^{17}$. Snacks contribute to about $20-25 \%$ of total energy intake in countries like the US and UK ${ }^{18}$. However, there is little evidence that a higher frequency of eating per se is a potential cause of obesity. Cross-sectional studies tend to show a negative relationship or no relationship between meal frequency and BMI ${ }^{19}$. Low eating frequency may, of 
course, be a response to obesity rather than a cause. Experimental studies have found mixed results on the degree of caloric compensation that people make at meal time in response to a prior snack with some studies Diet, nutrition and the prevention of excess weight gain and obesity ${ }^{20}$ showing more complete compensation among lean people ${ }^{19}$. studies would suggest that a 'flexible restraint' eating pattern is associated with a lower risk of weight gain whereas a 'rigid restraint/periodic disinhibition' pattern is associated with a greater risk of weight gain ${ }^{21}$. Binge eating disorders are significantly more common in obesity in cross-sectional studies. The relationships between these dietary patterns and weight gain or obesity is complex with both cause and effect relationships likely.

Obesity has reached epidemic proportions in India in the 21 st century; affecting $5 \%$ of the country's population $^{22}$.India is following a trend of other developing countries that are steadily becoming more obese. Morbid obesity has acquired epidemic proportions in the country. This is only the tip of an ice berg and the incidence is growing, according to medical experts ${ }^{22}$. Unhealthy, processed food has become much more accessible following India's continued integration in global food markets.

\section{Assessment of obesity:}

One of the most commonly applied methods is calculating body mass index (BMI) for which we need to check weight and height recordings ${ }^{23}$. Both the measurements i.e. height and weight are necessary to record. Ideally BMI must be in normal range, that's between 18.5 to $24.9 \mathrm{~kg} / \mathrm{m}^{2}{ }^{24}$. If BMI is less than 18.5 $\mathrm{kg} / \mathrm{m}^{2}$, there is no risk of obesity, but definitely the person is under-nourished (malnourished) and susceptible to various diseases due to deficiency of various nutrients. But if BMI is above $25 \mathrm{~kg} / \mathrm{m}^{2}$, then the person has risk of getting other diseases and proportionately more, with increasing BMI.

\begin{tabular}{|c|c|c|}
\hline Classification & $\begin{array}{r}\mathrm{BMI} \\
\left(\mathrm{kg} / \mathrm{m}^{2}\right)\end{array}$ & Risk of co- morbidities \\
\hline Underweight & $<18.5$ & 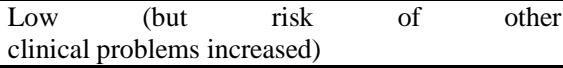 \\
\hline Normal range & $18.5--24.9$ & Average \\
\hline Overweight & $\geq 25.0$ & \\
\hline Pre-obese & $25.0--29.9$ & Increased \\
\hline Obese class I & $30.0--34.9$ & Moderate \\
\hline Obese class II & $35.0--39.9$ & Severe \\
\hline Obese class III & $\geq 40.0$ & Very severe \\
\hline
\end{tabular}

\section{Material And Methods}

This is a population based cross sectional study conducted over a period of one year from February2009 to March 2010, the study was conducted in selected villages and one town of Kashmir valley. The valley of Kashmir is situated in North West of India at an altitude of 4000 meters between $32^{\circ}-15^{\prime}$ and 37.5 north latitude and $80^{\circ}-20^{\prime}$ east longitude.

Multistage and multiphasic sampling technique was utilized in this study to screen the obese subjects and in which first of all people in the selected sample had been assessed for obesity, based on WHO classification of obesity according to BMI. Socio-economic parameters and physical activity were noted in all the subjects of 18-45 years of age.In the second phase only those subjects found to be obese had been assessed for their dietary intake and investigations for blood cholesterol and serum triglycerides was done. Every effort was made to take a detailed history; clinical examination was done, of those people who were found to be obese, to access the magnitude of obesity in age group of 18-45 years.

The approach to the study was made by selecting $3 \%$ sample of villages from all the blocks excluding urban areas .First of all the sampling frame of 449 villages was prepared where from a sample of 13 villages (comprising total population of 15664 and the population in the age group of 18-45 years were 3800), with the help of three digit random sample technique was taken. The total urban population of Selected area was 4765 and the population in the age group 18-45 years was 1307. All the households falling in the selected rural and urban areas, which were 4020 in number were completely enumerated and after line listing the households, each household was visited and only the subjects having age of 18-45 years were included in this study and this comprised of 5107 subjects, then identified obese cases with the help of height and weight techniques.

Only those people who had simple obesity were included in the study. People having secondary obesity, drug induced obesity and pregnant ladies were excluded from this study. 


\section{Survey Data}

Anthropometric Data

Standard techniques were adopted for obtaining anthropometric measurements. Weight was measured with light clothing but without shoes to the nearest $0.1 \mathrm{Kg}$. using a portable standard weight scale. Height had been measured using a portable height scale. The subjects were instructed to stand bare feet with their head in an upright position. The reading was noted to the nearest $0.1 \mathrm{~cm}$. From the ratio of weight to height square, the Body Mass Index (BMI) will be determined where BMI $=$ Weight $(\mathrm{kg}) / \mathrm{Height}^{2}(\mathrm{~m})$. The scales were checked for accuracy before starting the survey and after and then rechecked periodically.

Socio-Economic and Life Style Data-The demographic data such as age, sex, education, occupation, and financial income (household total income per month) were compiled. Information on physical activity, smoking, dietary habits, and self-reported health problems were also obtained from the same questionnaire.

Dietary Data.-All the obese respondents were asked to report all foods and beverages consumed over the previous 24 hour time period (midnight to midnight). For accuracy, respondents were first asked to recall all food items in an uninterrupted manner, and then specific probes for the types of foods, preparation ingredients, and the amount were verified for the food items mentioned. Portion sizes were estimated using bowls and plates regularly used among Kashmiri households, and information on food consumed away from home were also been collected through direct questions and recorded in portion sizes ${ }^{27-30}$. The portion sizes were converted into grams before the data entry, and the energy intake was compared with the recommended dietary allowances for Indians by Indian Council of Medical Research (ICMR), $2009^{31}$.An unquantified food frequency questionnaire (FFQ) was developed to assess the usual dietary intake over a week period to minimize the effect of day- to-day variation in dietary intake ${ }^{32,33}$. Food frequency of the diet intake was classified as never, 1 time, 2-4 times, 5-6 times a week, once or more daily for all age group.

\section{Statistical Analysis:-}

Entire data was subjected to suitable standard statistical technique. Univariate analysis was done applying specific tests, wherever applicable.

\section{Observations}

Table-1-Daily energy intake of the obese people in the studied population compared to the recommended dietary allowances for Indians as per ICMR guidelines.

\begin{tabular}{|c|c|c|c|c|c|c|c|c|}
\hline 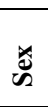 & Category & $\begin{array}{l}\text { Requirement } \\
\text { (kcal/d) }\end{array}$ & $\begin{array}{l}\text { Mean Actual } \\
\text { Intake (kcal/d) }\end{array}$ & $\begin{array}{l}\text { Deviation From } \\
\text { Requirement }\end{array}$ & $\begin{array}{l}\text { t- } \\
\text { value }\end{array}$ & $\begin{array}{l}\text { Fat } \\
\text { Intake } \\
(\%)\end{array}$ & $\begin{array}{l}\text { Protein } \\
\text { Intake } \\
(\%)\end{array}$ & $\begin{array}{l}\text { Carbohydrate } \\
\text { Intake (\%) }\end{array}$ \\
\hline \multirow[b]{3}{*}{$\frac{0}{\tilde{J}}$} & $\begin{array}{l}\text { Sedentary } \\
\text { Work }\end{array}$ & 2320 & $2527 \pm 43.27$ & +207 & $*$ & $35 \%$ & $6.5 \%$ & $58.5 \%$ \\
\hline & $\begin{array}{l}\text { Moderate } \\
\text { Work }\end{array}$ & 2730 & $2973 \pm 29.45$ & +243 & $*$ & $33.4 \%$ & $6.2 \%$ & $61.4 \%$ \\
\hline & $\begin{array}{l}\text { Heavy } \\
\text { Work }\end{array}$ & 3490 & $3772 \pm 53.89$ & +282 & $*$ & $20.7 \%$ & $5.3 \%$ & $74 \%$ \\
\hline \multirow{3}{*}{ 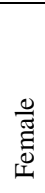 } & $\begin{array}{l}\text { Sedentary } \\
\text { Work }\end{array}$ & 1900 & $2237 \pm 39.66$ & +337 & $*$ & $37.2 \%$ & $5.1 \%$ & $57.7 \%$ \\
\hline & $\begin{array}{l}\text { Moderate } \\
\text { Work }\end{array}$ & 2230 & $2401 \pm 11.93$ & +171 & $*$ & $35.4 \%$ & $6.7 \%$ & $57.9 \%$ \\
\hline & $\begin{array}{l}\text { Heavy } \\
\text { Work }\end{array}$ & 2850 & $3099 \pm 69.56$ & +249 & $*$ & $27.8 \%$ & $6.8 \%$ & $65.4 \%$ \\
\hline
\end{tabular}

\section{Discussion}

The present study is a cross sectional study conducted in Kashmir province.). Where in 5107 people in the age group 18-45 were included out of 20429 people screened in a multiphasic sampling manner . The overall prevalence of obesity was $7.05 \%$ in our study which include 5107 people, in which 360 came out to be obese. Abbas et al $(2003)^{34}$ reported a prevalence of $7 \%$ obesity in their study .

Sang-Ah Lee et $\mathrm{al}^{35}$, after reviewing many studies on diet and obesity observed that the balance between the total energy intake and energy expenditure determine weight gain or loss. Further two Chinese cross sectional studies, Sakurai Y, Umeda T, Shinchi K et $\mathrm{al}^{36}$ and Hu G, Pekkannen H. Hanninen o et $\mathrm{al}^{37}$ have found that higher BMI (obesity) was related to higher energy intake and obese people have higher intake of fat and proteins containing foods. In our study based upon $24 \mathrm{hr}$. recall of dietary data, when compared to mean of energy intake as recommended by ICMR(Indian Council of Medical Research) guidelines ${ }^{31}$, it was found that obese people had their mean daily actual energy intake higher than required, showing a deviation from requirement on positive side. Obese people in our study were consuming fats more than recommended while as protein consumption was less. Similar pattern was observed by Abbas et al ${ }^{34}$, Khan et al ${ }^{38}$.

Megan A. McCrory, Paul J. Fuss, et al.2000 ${ }^{21}$. Stated in his study that; Energy density, palatability and dietary variety are important dietary components, and recent studies suggest that these dietary variables may play 
a more significant role than dietary fat in determining energy intake and body fatness. Further studies are required to investigate the relative influence of these and other dietary variables on weight regulation.Reza Amani; $2008^{39}$ concluded that there were no significant differences between consumption of food groups and different educational subclasses. Data obtained from semi-quantitative food frequency questionnaires revealed that (except bread, which is the main staple food in Iranian dietary pattern) the main food groups were inadequately consumed in daily meals. Daily consumption of the red meat was only seen in $8 \%$ of subjects. On the other hand, daily intake of hydrogenated fats, biscuits, and dates were reported by almost $30 \%$ of the women, two latter foods were being consumed as habitual snacks during work times. Furthermore, habitual intake of all types carbonated drinks and fatty sausages were observed in about one third of individuals. All of these dietary practices seem to be relevant to high energy intake.Noriko Sudo, et al , $2009^{40}$.Observed in his study that mean waist circumference was highest in "impulsive eater" compared with the "concerned about nutrition" segment. Those in the "busy cooking avoider" segment have a significantly higher energy intake compared with women in other attitude segments. Tailoring a weight management intervention according to attitude segments of midlife women may enhance effectiveness.

\section{Conclusion}

As populations become more urban and incomes rise, diets high in sugar, fat and animal products replace more traditional diets that were high in complex carbohydrates and fibre. Unique traditional food habits are being replaced by westernized fast foods, soft drinks and increased meat consumption. Homogenizations and westernization of the global diet has increased the energy density and this is particularly a problem for the poor in all countries who are at risk of both obesity and micronutrient deficiencies.

\section{Recommendations}

A 'flexible restraint' eating pattern is associated with a lower risk of weight gain whereas a 'rigid restraint/periodic disinhibition' pattern is associated with a greater risk of weight gain.So a 'flexible restraint' eating pattern should be encouraged .

\section{References}

[1]. Text Book of Medicine WYNGAARDEN Edwinl. Bierman 216.Obesity $17^{\text {th }}$ Edition.

[2]. World Health Organization ;Obesity; Preventing And Managing The Global Epidemic; Report Of a WHO Consultation WHO Pech Rep Sir;894;1x11,1-253,2000.

[3]. Javed A, Hasan H. Characteristics of diabetics patients. Ann King Edward Med 6(2): 196-9. J 2000;.Three Pacific Island Countries. J American Collage of Nutrition, vol. 11, No. 3: 283-293. 1992

[4]. Kumar P, Clark M. Clinical medicine. $4^{\text {th }}$ edition. $\quad$ Philadelphia: WB Sannders, 209. 1998.

[5]. Sood R.Gupta A.An epidemiological study of obesity in Shimla town.Indian Journal of Medical Sciences oct.50(10). 1996.

[6]. Stevens J. Impact of age on association between weight and mortality.Nutrition Review (May) 58(5) 129-37. 2000

[7]. Obesity: Preventing and Managing the Global Epidemic. Report of a WHO Consultation. WHO Technical Report Series No. 894. Geneva, Switzerland: WHO, 2000.

[8]. World Health Organization (WHO). Diet, Nutrition and the Prevention of Chronic Diseases. Report of a joint WHO/FAO expert consultation, Geneva: World Health Organization, Technical Report Series No. 916. 2003.

[9]. WHO/IASO/IOTF: The Asia-Pacific perspective redefining obesity and its treatment. Health Communications Australia: Melbourne. 2000

[10]. Seidell JC, Rissanen A, Prevalence of Obesity in Adults: The Global Epidemic. In: Bray GA, Bouchard C, eds. Handbook of Obesity, 2004 (In press).

[11]. Pena M, Bacallao J, ed. Obesity and Poverty: A New Public Health Challenge. Washington, DC: Pan American Health Organization (PAHO), 2000.

[12]. Popkin BM. The nutrition transition and obesity in the developing world. Journal of Nutrition 2001; 131(3): 871S-3S.

[13]. Drewnowski A. Nutrition transition and global dietary trends. Nutrition 2000; 16(7-8): 486-7.

[14]. Jung RT. Obesity as a disease. British Medical Bulletin 997;53(2): 307-21.

[15]. Wolf AM, Colditz GA. Social and economic effects of body weight in the United States. American Journal of Clinical Nutrition 1996; 63(3 Suppl): 466S-9S.

[16]. Egger G, Swinburn B. An "ecological” approach to the obesity pandemic. British Medical Journal 1997; 315(7106): 477-80.

[17]. Zizza C, Siega-Riz AM, Popkin BM. Significant increase in young adults' snacking between 1977-1978 and 1994-1996 represents a cause for concern! Preventive Medicine 2001; 32(4): 303-10.

[18]. Green SM, Burley VJ. The effects of snacking on energy intake and body weight. Nutrition Bulletin BNF 1996; $21: 103-7$.

[19]. Drummond S, Crombie N, Kirk T. A critique of the effects of snacking on body weight status. European Journal of Clinical Nutrition 1996; 50(12): 779-83.

[20]. Howarth NC, Saltzman E, Roberts SB. Dietary fiber and weight regulation. Nutrition Reviews 2001; 59(5): 129-39.

[21]. Megan A. McCrory, Paul J. Fuss, et al.2000. Journal of Nutrition. 2000;130:276S-279S.). (C) 2000 The American Society for Nutritional Sciences Dietary Determinants of Energy Intake and Weight Regulation in Healthy Adults.

[22]. "India facing obesity epidemic: experts". The Hindu. 2007-10-121).

[23]. World Health Organization. Obesity and Overweighthttp://www.who.int; 2005

[24]. Report of a WHO Expert Committee. Physical Status: The use and Interpretation of Anthropoetry. WHO Technical ReportSeries (854). Geneva, 1995

[25]. WORLD HEALTH ORGANISATION.Obesity and Overweight .classification.who.int.2005.

[26]. Park`s Textbook of Preventive and Social Medicine, $20^{\text {th }}$ edition page 347. 2009 
[27]. Briefel R.R., Mc Dowell M.A., Alaimo K., et. Al. : Total energy intake of the US population : the third National Health and Nutrition Examination Survey, 1988- 1991. Am J Clin Nut, 1995; 62 (suppl): 1072S-80S.

[28]. Ghadirian P., Shatenstein B. : Nutrient Patterns Nutritional Adequacy, and Comparisons with Nutrition Recommendations Among French- Canadian Adults in Montreal. J American College of Nutrition, 15, No. $3: 255$ - 263;1996.

[29]. Tian H.G., Nan Y., Hu G., et.al. : Dietary Survey in a Chinese Population. European J. Clinical Nutrition. 49, 26-32. 1995.

[30]. 30)Taylor R., Badcock J., King H., et. Al. : Dietary Intake, Exercise, Obesity and Non communicable Diseases in Rural and Urban 44).Populations of Three Pacific Island Countries. J American Collage of Nutrition, vol. 11, No. 3: 283-293. 1992.

[31]. NUTRIENT REQUIREMENTS AND RECOMMENDED DIETARY ALLOWANCES FOR INDIANS A Report of the Expert Group of the Indian Council of Medical Research 2009 NATIONAL INSTITUTE OF NUTRITION Indian Council of Medical Research Jamai-Osmania PO, Hyderabad - 500 604. 32).

[32]. Briefel R, Bialostosky K, Kennedy-Stephenson J, McDowell M, Ervin R, and Wright J, 2000. Zinc Intake of th U.S. Population: Findings from the Third National Health and Nutrition Examination Survey, 1988-1994. Journal of Nutrition; 130:1367S-1373S

[33]. Faber M, Jogessar VB and Benade AJS, Nutritional status and dietary intakes of children aged 2-5 years and their caregivers in a rural South African community. International Journal of Food Science an 31 Nutrition; 52,401-411. 2001.

[34]. Muhammad Abbas,Alam Khan and M.Muzaffar Ali Khan Khattak.Prevalence of Obesity In Male in Relation to Dietary intake And Physical Activity Level.Pak journal of Nutrition 2 (4);234-237,2003.

[35]. Sang- Ah Lee, Wanqing Wen, Wang Hong Xu, Wei Zheng, Honglan Li, Gong Yang, Yong- Bing Xiang, and Xiao-Ou Shu.Prevalence of obesity and correlations with lifestyle and dietary factors in Chinese men.Obesity (Silver Spring). Author manuscript available in PMC2000 June 1Published in final edited form as:Obesity (Silver Spring) 2008 June 16(60 14401441Published online 2008 March 20 doi:10 1038/oby/2008.58

[36]. Sakurai Y, Umeda T, Shinchi K, Honjo S, Wakabayashi K, Todoroki I, Nishikawa H, Ogawa S, Katsurada M. Relation of total and beverage-specific alcohol intake to body mass index and waist-to-hip ratio: a study of self-defense officials in Japan. Eur J Epidemiol. 1997,13:893-8(PubMed).

[37]. Hu G, Pekkannen H. Hanninen o. Tian H, Jin R. Comparison of dietary and non - dietary risk factors in overweight and normalweight Chinese adults. Br J Nutri; 2002;88;91-73.(PubMed).

[38]. Aien khan Afridi and Alam Khan Department of Human Nutrition, NWFP, Agricultural University, Peshawar. Prevalence and Etiology of Obesity - An Overview Pak. Journal of Nutrition 3 (1): 14-25, 2004@ Asian Network for Scientific Information 2004.E-mail: alamkhandr@yahoo.com.

[39]. Reza Amani ,Fereshteh Boustani.Prevalance of obesity and dietary practices in Jondi-Shapour university female personnel, Ahvaz,Iran.Pak J Med Sci October-December 2008 (Part-I) Vol.24 No.5 748-752

[40]. Noriko Sudo , Courtney Perry ,Marla Reicks .Adequacy of Dietary Intake Information Obtained from Mailed Food Records Differed by Weight Status and Not Education Level of Midlife Women.Journal of the American Dietetic Association.Volume 110, Issue 1 ,pages 95-100,January 2010. 